\title{
ESBOZO DE LAS MIGRACIONES INTERNAS EN EL SIGLO XX Y PRIMERA DÉCADA DEL SIGLO XXI Y SU RELACIÓN CON LOS MODELOS DE DESARROLLO ECONÓMICO EN EL PERÚ
}

\section{OUTLINE OF INTERNAL MIGRATION IN THE TWENTIETH CENTURY AND THE FIRST DECADE OF THE CENTURY AND ITS RELATION TO THE MODELS OF ECONOMIC DEVELOPMENT IN PERU}

\author{
${ }^{1}$ Ernesto Hector Maguiña Salinas
}

\begin{abstract}
Resumen
El presente artículo de investigación describe sucintamente, desde una visión de proceso, los cambios demográficos que evidencian las migraciones internas a lo largo del siglo XX y primer decenio del siglo XXI. Estos cambios se relacionan con las especificidades que presenta el desarrollo del capitalismo en el Perú evidenciados en sus diferentes modelos macro económicos.

Señala la dinámica migratoria y sus diversos impactos demográficos en el proceso de urbanización, crecimiento de las ciudades y en el despoblamiento del campo.
\end{abstract}

Palabras clave: Población, migración, expulsión, atracción, economía, urbanización, ciudades, modelos de desarrollo.

\begin{abstract}
This research paper briefly describes the demographic changes that show internal migration seen from a process view, throughout the twentieth century and the first decade of the XXI century. These changes relate to the specific presenting the development of capitalism in Peru linked specifically to their different economic models. Notes migration dynamics and their impacts on various demographic urbanization, growth of its cities and depopulation of the countryside.
\end{abstract}

Keys words: Population, migration, expulsion, attraction, economy, development, city development models.

\section{Introducción}

El pato Las migraciones internas en nuestra sociedad remontan históricamente desde la época prehispánica, adquiriendo especial relevancia en el siglo XX. En esta centuria los movimientos de población se dinamizan, especialmente, desde su segunda mitad, acelerándose hasta la década de 1970 y declinando significativamente en las décadas de 1990 y 2000. Esto ocurre en un contexto de desarrollo del capitalismo ligado a sus diferentes modelos macro económicos.

A lo largo del siglo XX han ocurrido modificaciones importantes en nuestra estructura productiva, aunque siempre ligada a una matriz primaria-exportadora, alternándose periodos de estabilidad y bonanza económica con otros de inestabilidad y crisis, teniendo diversas repercusiones en los movimientos migratorios. Estos periodos se enmarcan dentro de teorías como la neoclásica de las ventajas comparativas, vigentes hasta finales de la década de 1940, el modelo de industrialización, inspirada por la CEPAL en la década de 1950, y el modelo neoliberal que resurge en la década de 1980 ante el fracaso del modelo de industrialización basado en las propuestas del Consenso de Washington y del Banco Mundial. Constituye una vuelta a la economía extractivista. El objetivo de este trabajo es: Relacionar las tendencias de las migraciones internas dentro de los modelos primario-exportador, de industrialización y neoliberal.

Nuestra principal fuente de datos se basa en los censos nacionales de población realizados de 1940 al 2007. También en los censos de población de Lima de 1920 y 1931. Se ejecutaron algunas proyecciones de población hasta el 2011.

\section{Amanera de marco de referencia}

Las migraciones internas históricamente, desde la primera mitad del siglo XX, han sido explicadas desde diferentes concepciones o enfoques. Tenemos enfoques vinculados a los factores de atracción y expulsión de 
población. Según Singer (1), son de dos órdenes: de cambio y de estancamiento. El primero se relaciona con la introducción de economías modernas en determinados espacios $\mathrm{y}$, el segundo, con la presión demográfica sobre la existencia de áreas cultivables, limitada por la escasez de tierras, escasa productividad y rentabilidad. Los factores de atracción están vinculados a los procesos de modernización e industrialización que favorecen mayoritariamente a las ciudades. Por otro lado, el atraso se ubica en la mayor parte del campo, con un agro deteriorado que expulsa población. Este enfoque para varios estudiosos era insuficiente dado los cambios que se venían dando en las relaciones urbano-rurales, sobre todo en la década de 1990. Con el enfoque de la nueva ruralidad Revesz y otros afirman que las diferencias urbano-rurales declinan con un aumento demográfico en los centros poblados intermedios y menores, donde lo urbano y lo rural se articulan más (3) declina el sesgo sectorial de desarrollo rural y la desagrarización del mundo rural. Enfatiza la multifuncionalidad del territorio, la pluriactividad rural, el concepto de población rural, la amplia gama de espacios productivos, valorándose más el minifundio como algo positivo.

Richard Web (4) afirma que lo rural evidencia un progreso y mas importancia económica a partir del incremento y mejoramiento de las vías de comunicación, dinamizando la producción y comercialización agropecuaria beneficiándose los poblados, sobre todo, las capitales de distrito, vecinos a las áreas de producción. Pero lo rural tiene un despoblamiento relativo y absoluto, sobre todo entre el 2007-2011 debido a su atraso y pobreza. Las ciudades atraen migrantes a pesar de descender, incluso en cifras absolutas, como algunas ciudades menores.

Entre 1990-2010 declina más las migraciones internas y aumenta la emigración al extranjero. Nuestra hipótesis es: "El volumen y direccionalidad de las migraciones internas en el siglo XX están influidos por los rasgos específicos de los modelos de desarrollo del capitalismo en el Perú"

\section{Las migraciones internas dentro del modelo primario-exportador}

Según Faria, citado por Carlos Barba, este modelo tiene como telón de fondo la teoría neoclásica de la división internacional óptima del comercio y el trabajo que sostenía que la especialización en la producción de alimentos y materias primas para los grandes centros industriales no era perjudicial. Se creía que el intercambio internacional permitiría que los países especializados en productos del sector primario participaran de los beneficios del progreso técnico, ya sea por la baja de precios o por el aumento de ingresos. Se aducía que industrializarse sería un error ya que la escasa eficiencia de estos países provocaría la pérdida de la ventaja convencional del comercio internacional para América Latina (5).
Pennano afirma que las dos primeras décadas del siglo XX se caracterizaron por una significativa expansión y "en gran escala de los dominios agrícolas, destrucción de la producción interna, extensión del caciquismo regional, etc. Este proceso originó la formación de las oligarquías costeñas en el norte con los cultivos de azúcar y expansión de vías ferroviarias, en el centro, con la consolidación de la Cerro, la Peruvian y el cobre, y en el sur con la mediana propiedad y el poder comercial lanero de Arequipa"(6). Entre 1899 y 1915, aumentaron las exportaciones de algodón y azúcar. El algodón, el azúcar y el cobre en plena guerra mundial cubrieron más del $80 \%$ de las exportaciones peruanas, consolidando el capitalismo en estos sectores claves. Entre 1914 y 1919 se triplicaron las exportaciones, siendo aún más hasta 1929, declinando después.

Las inversiones extranjeras en 1914 la encabezaba Inglaterra con 121 millones de dólares, seguido de Estados Unidos con 58 millones y Francia un millón (7). Después, en 1919 las inversiones norteamericanas llegaron a 110 millones y en 1929 a 124 millones, localizadas principalmente en la minería y el petróleo. Después de 1932, superada la crisis mundial, volvió a aumentar el valor de las exportaciones de algodón, azúcar, cobre, petróleo y lanas. Entre 1932 y 1939 se duplicaron los envíos de lana y algodón y cuadriplicó los de cobre. La segunda guerra mundial privilegió las exportaciones mineras y redujo las importaciones de manufacturas sirviendo para generar una mayor producción nacional industrial.

En el oncenio de Leguía se construyó la carretera Panamericana. A mediados de 1936 se erigieron más de 1,000 millas de nuevas vías, como la de ArequipaPuno. Se realizó grandes gastos en las áreas de menor desarrollo como la sierra sur para incorporarla política y económicamente al eje capitalista de la costa. En la década de 1940 se hizo la carretera Cusco-Puerto Maldonado y la vía Lima-Pucallpa. Entre 1925 y 1940 la red vial aumentó de 4,000 a 22,600 kilómetros.

\subsection{Urbanización y migraciones internas}

Según Carlos Contreras la segunda mitad del siglo XIX estuvo marcada por una relativa fortaleza de la sociedad rural tradicional expresada en el sólido control que los terratenientes tenían sobre sus peones y, sobre todo, los campesinos de sus tierras y, en general, de los medios agrarios para su reproducción. Esta solidez se vio reforzada por una favorable relación hombre-tierra, especialmente en la región serrana (8). Empezando el siglo XX se estimó la población peruana en 3'700,000 habitantes, correspondiendo $70 \%$ al ámbito rural.

La hacienda tradicional influía en el campesino, no sólo del que vivía en su interior, también en comunidades y pueblos vecinos. Las migraciones lentamente fueron rompiendo este control, sobre todo en la sierra. En las primeras décadas del siglo XX muchos campesinos van 
a las grandes haciendas azucareras y algodoneras de la costa y a los principales centros mineros de la sierra central.

En 1940, el 65\% del país era rural. En 1950, aumentó la población del ámbito urbano (41\%), enfatizando el proceso de urbanización, pero con un creciente deterioro de la estructura agraria tradicional andina y una pérdida de control de los hacendados sobre el campesinado ayudando a su expulsión. El aumento de vías, la difusión urbana, la limitación de la producción de alimentos contribuyeron a presionar sobre el campo, dinamizando las migraciones rurales-urbanas.

\subsubsection{Urbanización}

Este proceso hasta 1920 fue débil, sólo relucía Lima, entre 1908-1920 aumentó de 140,000 a 173,000 habitantes. En 1905 el Callao tenía 33,879 personas, Ayacucho en 1908 registró 14,364, Arequipa (1917) más de 30,000, Ica obtenía 15,000, Cajamarca 14,000, Abancay 15,000, Cusco en 1914 agrupó a 30,000 individuos. Iquitos, entre 1912-1932, creció de 15,000 a 24,500 habitantes. En 1940, Arequipa obtuvo 81,000 personas, Cusco 41,000 e Iquitos 32,000. El Callao en 1931 tenía 72,000 y Lima 372,000 .

Debido a la agricultura de exportación se formaron poblados en haciendas grandes como Casagrande, Laredo, Cayaltí, Cartavio y Tumán. Igualmente con la industria azucarera surgieron los centros comerciales de Ascope y Trujillo. En 1916 varios pueblos del valle de Chicama duplicaron su población como Chicama de 1,953 a 5,000 habitantes, Chocope de 2,554 a 6,000. En Trujillo (1923), vivían 23,000 personas, aumentando en 1940 a 37,000. Debido a la minería crecieron los poblados de Casapalca y Morococha, siendo mayor en Cerro de Pasco $(18,000)$ y La Oroya $(13,500)$ en 1940. En el centro, Huancayo se convirtió en una importante ciudad con la ejecución de la carretera central.

\subsubsection{Migración rural-urbana}

Desde la década de 1930 las migraciones se acrecentaron en algunas ciudades. En 1940 el 36\% de la población de Lima-Callao era foránea, el $27 \%$ en Trujillo, 25\%, en Chiclayo, 20,0\% en Iquitos. En 1950 la migración se elevó más en Lima-Callao (40,0\%), Trujillo (38\%), Puno (33,5\%), Chiclayo (32\%) y Cusco (32\%). La capital, superaba el millón de habitantes, siendo 400,000 migrantes, principalmente venían de áreas cercanas. Las migraciones a Trujillo tuvo que ver con la expulsión de población del latifundio capitalista. En Arequipa la migración no fue masiva. En esa región hubo mayor intercambio entre hacendados, medianos y pequeños propietarios, comerciantes, etc. interactuando y absorbiendo personas en diferentes partes de la región.

\subsubsection{Migración rural-rural}

En las primeras décadas del siglo XX, con el avance del capitalismo en el país, afín a la explotación, producción y exportación de materias primas, en el campo hubo dos procesos sociales y demográficos: El enganche y el yanaconazgo. Ambos ligados al problema de la escasez de fuerza de trabajo. El enganche (9) fue el componente más importante de las migraciones ruralrural. Comenzó a revitalizarse en el último decenio del siglo XIX, asumiendo después un rol más decisivo, fue imprescindible en el funcionamiento de las economías de exportación, dentro de un proceso de modernización y capitalización de la agricultura en la costa y mineras de la sierra central. El crecimiento de la economía, sobre la base de las exportaciones, requirió hasta cerca de la tercera década del siglo XX de una importante cantidad de mano obra indígena.

En la costa el trabajador enganchado fue el eje productivo de las grandes plantaciones de azúcar. Igualmente fue muy importante en las minas de la sierra central y en la extracción del caucho en la selva baja. Importantes escenarios de mano de obra enganchada fueron el valle de Chicama, en la costa norte, el valle del Mantaro, en la sierra central y la selva en Loreto y Madre de Dios.

En la década de 1920 la actividad azucarera del valle de Chicama se convirtió en uno de los centros de producción más importantes del país con una mano de obra que superaba los 20,000 trabajadores, la mayoría migrantes provenientes de la sierra de La Libertad y Ancash. De otro lado, entre 1905 y 1919, el número de trabajadores mineros en el Perú aumentó de 9,651 a 22,000, llegando en 1928 a más de 27,000. Los trabajadores en la empresa Cerro de Pasco se ampliaron entre 1908 y 1920 de 5,166 a 7,840, elevándose en 1929 a 13,000,. Esto representó más del $47 \%$ de los mineros del país. La mayoría de los enganchados venía de la parte baja y norteña del valle del Mantaro.

En relación al caucho, éste tuvo corta duración (18851920) llegando a su mayor valor de exportación en 1912, descendiendo después y colapsando en 1920. La extracción del caucho movilizó en la selva de Loreto a muchos nativos y a otros de zonas contiguas como San Martín y Amazonas. En Madre de Dios los caucheros enganchados venían mayormente de Puno, Cusco y Bolivia.

El yanaconazgo (10) subsistió como un rezago colonial, cobrando importancia a fines del siglo XIX en las haciendas algodoneras de la costa central, donde la agricultura no se había desarrollado mucho, operando también como una forma de captación de mano de obra necesaria para su producción y exportación. 
La concentración de la propiedad fue más evidente en las haciendas cañeras, con un notable progreso técnico y productivo. Con el algodón, la propiedad estuvo menos concentrada debido a su producción era simple. En los primeros años de la década de 1920, el algodón adquirió una gran importancia por sus altos precios en el mercado mundial, pero no estuvo acompañado de una adecuada tecnología. En los valles de la costa central hubo nativos y japoneses que laboraban como yanaconas ocupando grandes extensiones de tierras.

Por la expansión de las haciendas numerosos campesinos perdieron sus tierras, como en Piura. Cerca de 80,000 se convirtieron en asalariados desplazándose por la costa buscando empleo. Unos laboraron en la costa central cosechando algodón, regresando a Piura para las cosechas de julio y agosto. Otros se instalaron cerca de las haciendas azucareras de Lambayeque y La Libertad. Hubo quienes laboraban en el Alto Piura en distintas haciendas arroceras. Muchos migrantes trabajaron en los yacimientos petroleros de Talara (11). Desde finales de la década de 1920 el enganche fue volviéndose innecesario en las haciendas azucareras y en los centros mineros. Muchos trabajadores se convirtieron en obreros permanentes. En las haciendas algodoneras los yanaconas fueron suplidos por una masa asalariada. Muchos fueron expulsados por hacendados temerosos de perder sus tierras.

\subsubsection{Las migraciones en Lima y Callao}

Como consecuencia del aumento de las exportaciones, Lima durante las primeras décadas del siglo XX experimentó un crecimiento importante diversificando sus actividades productivas. La tasa demográfica de Lima aumentó moderadamente en los periodos 1903-1908 $(1,6 \%), 1908-1920(1,7 \%)$ y rápidamente entre 19201931 (4,7\%) donde hubieron mas provincianos. Muchos jóvenes llegaron a Lima para estudiar en universidades, escuelas técnicas y profesionales, predominantemente de sectores sociales medios urbanos de la costa y la sierra o a élites señoriales. Hubo también grupos de poder regionales mayormente vinculados a las haciendas tradicionales. A ellos se unieron otros jóvenes de clase media, "menospreciados y completamente ignorados por los representantes regionales" (12). Ellos fueron la primera oleada de migrantes.

En la década de 1920 en Lima aumentó el centralismo y el desarrollo desigual. Entre 1920 y 1931, en conjunto, Lima y Callao creció de 276,000 a 444,000 habitantes. Hasta 1920 el aporte migratorio constituyó el 35\% y en 1931 el 36\%. La capital se fue convirtiendo en sede de una población en constante aumento, ampliando su limitado desarrollo industrial estimulado por el mercado de consumo de manufacturas y de comercio y los servicios. Hasta 1940, Lima- Callao continuó su rápido avance demográfico, representando la migración el
$36,5 \%$ de la población capitalina, la cual en su mayoría eran de clase medias urbana costeñas y serranas. Pocos fueron de origen campesino y oligárquico.

\section{Las migraciones internas dentro del modelo de industrialización}

Este modelo se basó en la perspectiva cepaliana que propuso modificar la estructura agropecuaria, eje del viejo esquema primario-exportador, lograr una distribución equitativa del ingreso, absorber económicamente a los grupos desposeídos a través del proceso de industrialización e integrarlos socialmente a través de políticas de promoción del empleo formal (13).

La expansión del sistema capitalista mundial después de la Segunda Guerra Mundial, condicionó en el país un proceso de desarrollo industrial importante, basándose en la situación favorable creada por los precios de sus exportaciones debido a la guerra de Corea y por la difusión de políticas de industrialización por parte de organismos internacionales. Se realizaron esfuerzos de diversificación con énfasis en la producción de bienes de consumo no duraderos como alimentos, calzados, textiles, bebidas, agro-industria, harina y aceite de pescado, etc. También en la producción de bienes duraderos como química básica, metalurgia y siderurgia donde habían grandes inversiones extranjeras. Asimismo fue importante la inversión en infraestructura básica de transportes y comunicaciones pero, sobre todo, en el sector minero que era el predominante.

El crecimiento industrial por los primeros años de la década de 1950 fue de apoyo a la exportación (industrias extractivas) y poco relacionado con la sustitución de importaciones, pero a mediados de esa década surgieron tendencias orientadas a una industrialización de bienes de consumo. Hasta el año 1960 la expansión industrial se centró en la elaboración de productos de exportación de determinados tipos de bienes intermedios (sobre todo papel, productos químicos y cemento) y bienes de capital (para los sectores minero y pesquero). En la década de 1960 se extendió a la producción de bienes de consumo duraderos, vinculada básicamente a la industria de ensamblajes. Tanto en el desarrollo de las exportaciones principalmente mineras, y, en menor escala, agrícolas y pesqueras, además de las industrias tradicionales y nuevas, ha sido importante el aporte de las inversiones extranjeras...Hubo enormes inversiones entre 195064 en los yacimientos de cobre de Toquepala y hierro de Marcona (14). La minería repuntó con la planta de Marcona (1953), la siderúrgica de Chimbote (1958) y la fundición de Ilo (1960). La industria de harina de pescado, entre 1965 y 1970, representó el 28\% y 32\%, respectivamente, del total de las exportaciones. En 1971 generó el 35\% de las divisas nacionales. 
Los primeros años de la década de 1970 se vigorizó el proceso de sustitución de importaciones, creando un conjunto de barreras proteccionistas para favorecer la industria nacional, buscando con ello consolidar a una industria nacional. Esos años pasaron dentro de una estabilidad de la economía y un mayor bienestar de ciertos sectores sociales del país. En el periodo 1940-1976 la red vial se amplió de 22,600 a 60,000 kilómetros, aunque el $90 \%$ estaba sin asfaltar (15)

En el quinquenio 1975-1980 hubo una retracción económica, disminuyendo el crecimiento del PBI, amortiguado por el sector minero que tuvo un incremento notable, debido básicamente a los proyectos cupríferos de Cuajone y Cerro Verde, en 1976, y al funcionamiento del Oleoducto petrolero Nor Peruano, en 1977. En la década de 1980 la economía decreció rápidamente, se redujo la inversión, precipitó la inflación, se deterioró el salario real, expandiéndose la informalidad. Todo esto acontecía en un contexto de violencia política.

\subsection{La estructura productiva agraria}

Entre 1961 y 1972 las unidades agropecuarias en el Perú aumentaron de 869,945 a 1'389,888. También la superficie agropecuaria lo hizo de 17'722,044 a 23'545,349 hectáreas (16). La mayor parte de las unidades y superficie agropecuaria se concentraban en la sierra. En las décadas de 1950 y 1960 dominaban las haciendas y que en 1961, constituían el 2,2\% de las unidades agropecuarias pero eran propietarios del $87 \%$ de la superficie agropecuaria. En la sierra prevalecía la hacienda tradicional y en la costa la hacienda moderna. Por otro lado, existían pequeños agricultores subordinados a los primeros que detentaban el $82 \%$ de las unidades agropecuarias menores de 5 hectáreas, pero apenas eran propietarios de menos del $6 \%$ de la superficie agropecuaria.

El agro serrano carecía de incentivos acentuando su crisis y presión demográfica sobre las escasas tierras de cultivo, además las técnicas de producción, ampliación de áreas de cultivos y forma de tenencia de la tierra eran deficientes.

En la década del 70, hubo algunos cambios estructurales de nuestra sociedad, siendo la más importante la Reforma Agraria, orientada a cancelar las relaciones injustas de explotación de la tierra, especialmente en la región andina. Las grandes haciendas son liquidadas convirtiéndose en cooperativas agrarias y sociedades de interés social, sin embargo, sus beneficiarios fueron una minoría, no alterándose mucho las formas de explotación agrícola. En 1972 los predios menores de 5 hectáreas constituían el $78 \%$ de las unidades agropecuarias y apenas controlaban el $7 \%$ del total de tierras. Las tierras de 50 hectáreas y más encarnaban el $2 \%$ del total de predios, pero poseían más del 79\% de las tierras.

\subsection{Urbanización y migraciones internas}

\subsubsection{Urbanización}

Desde la segunda mitad del siglo XX, se desplegó en la sociedad peruana un masivo y acelerado proceso de urbanización, especialmente entre las décadas de 1950 a 1970. Varias de sus características fueron similares a muchos países de América Latina, siendo las migraciones parte importante de ellas.

La industrialización se localizó principalmente en los centros costeros, sus efectos en el mercado tendieron a expandirse hacia las áreas rurales que se articularon a los principales centros regionales como Trujillo, Chiclayo y Piura, en el norte, además de Arequipa, en la sierra sur, e Iquitos, en el oriente. En este periodo la tasa de crecimiento demográfico fue bastante elevada en Chimbote $(13,4 \%)$, por el inicio del boom de la pesca en la década de 1950, llegando a esta ciudad de millares de migrantes. También a Pucallpa $(12,1 \%)$ se movilizaron de distintos lugares debido a la vía que conecta la costa, la sierra y la selva baja.

En la década del 60 se profundizaron las tendencias iniciadas en las décadas anteriores, con un rápido crecimiento de las áreas urbanas y un lento aumento acompañado de un descenso relativo de las poblaciones rurales. En los primeros años de la década de 1970 la población era mayoritariamente urbana $(60 \%)$ pero concentrada especialmente en ciudades grandes y medianas. El mayor dinamismo urbano se apreció entre 1961 y 1972, donde alcanzó una alta tasa de crecimiento demográfico (5,0\%). El campo alcanzó apenas el 0,5\%. El intenso proceso de urbanización se relacionó con una mayor fecundidad que aceleró el crecimiento poblacional del país, llegando a su nivel más elevado $(2,8 \%)$.

Específicamente, en la década de 1960 el crecimiento demográfico de la capital del país se aceleró (5,5\%), al igual que en otras ciudades grandes como Arequipa (6,3\%), Chiclayo (5,8\%), pero sobre todo Trujillo $(8,1 \%)$. Este dinamismo fue más significativo en Chimbote $(9,4 \%)$, Tingo María (9,1\%), Pucallpa (7,5\%) y Cerro de Pasco (7,5\%), ciudades con importantes actividades extractivas pesqueras, forestales y mineras que atraían población. El proceso de urbanización del país prosiguió en la década de 1970, pero con una relativa menor intensidad debido básicamente a una rebaja de la fecundidad y a una mayor apertura de la población, sobre todo andina, a la selva alta. Entre 1972-1981 la tasa demográfica urbana fue de $3,6 \%$, mientras que la rural llegó a $0,8 \%$.

En la década de 1970 la tasa de crecimiento de Lima Metropolitana también fue alta decreciente $(3,6 \%)$. En este decenio el ímpetu demográfico también declinó relativamente en ciudades grandes como Arequipa $(4,1 \%)$, Chiclayo $(5,1 \%)$ y Trujillo $(4,4)$ o intermedias como Iquitos $(5,5)$, pero conservándose alto. En cambio 
en otras ciudades como Piura (5,7\%) y Cuzco $(4,8 \%)$ este ímpetu se aceleró. Cabe destacar la elevada tasa de crecimiento de algunas ciudades menores como Chincha $(11,3 \%)$, Tingo María (10,6\%) y Puerto Maldonado $(10,0 \%)$ ligado al desarrollo de las actividades agrícolas, forestales y mineras.

En la década de 1980 el proceso de urbanización tuvo un ritmo de crecimiento demográfico alto aunque decreciente (2,8\%). Por esos años siguió declinando el crecimiento poblacional de las ciudades grandes y algunas intermedias, pero aumentó rápidamente en ciudades menores, pequeñas y otras intermedias. Todo esto debido esencialmente a una reorientación y ampliación de las migraciones, en parte relacionados con la violencia política y el narcotráfico. La esfera urbana se amplió configurando un interesante proceso de urbanización secundaria.

Entre 1981 y 1993, ciudades grandes y algunas intermedias como Arequipa (2,8\%), Trujillo (3,1\%), Chiclayo (3,3\%), Piura (2,4\%), Iquitos (3,6\%), Ica (2,9\%), Cuzco (2,8\%), entre otras, seguían mostrando un ímpetu demográfico alto pero decreciente. También sucedía con la capital de la República (2,7\%). En contraposición, en otros lugares del país se ampliaba con mucha pujanza espacios de atracción, sobre todo, en la selva rural, cuya economía se relacionaba principalmente con la producción y comercialización ilegal de la coca. Esto sucedió especialmente en los departamentos de Ucayali y San Martín donde la población del campo tuvo altas tasas de crecimiento $(5,1 \%$ y $3,8 \%$, respectivamente). Ciudades intermedias, menores y pequeñas se expandieron como Pucallpa (5,6\%), Huánuco $(5,6 \%)$, Tarapoto $(6,9 \%)$, Abancay (7,4\%), Huancavelica (3,3\%), Moyobamba (4,6\%), Moquegua (4,8\%), Huancayo (3,8\%), etc. Siendo sorprendente en Tocache (9,3\%) y Aguaytía (17,7\%), crecimiento atribuido al narcotráfico. La mayoría de estas ciudades, localizados fuera de la costa, fueron focos regionales de atracción de población.

\subsubsection{Migraciones internas}

Entre 1940 y 1961 las migraciones en el Perú aumentaron significativamente, de 554,000 (otros estiman en 796,000) a 2’213,000 personas. Los peruanos que por lo menos se desplazaron una vez de una provincia a otra aumentaron al 22,3\%. En este periodo los migrantes en Lima-Callao crecieron del 36,5\% a 44,8. El desarrollo desigual aceleró más la contradicción entre el desarrollo urbano industrial y el atraso agrario serrano a través de: 1) la masiva migración hacia las ciudades costeñas, especialmente a Lima. 2) Las crecientes movilizaciones campesinas contra las grandes haciendas tomando tierras.

\subsubsection{Los saldos migratorios entre provincias}

De acuerdo a los resultados del Censo Nacional de Población del año1961 la migración entre provincias involucró a más de 2’200,000 personas. Las provincias del país (144) presentaban diferentes saldos migratorios (17). Así, 35 de ellas (24\%) registraban balances positivos, es decir atraían más población que la que expulsaban, encontrándose la mayoría en la costa, destacando por su volumen Lima-Callao (730,000), seguido de lejos por Santa (42,371), Jaén (32,881), La Convención (24,384), Coronel Portillo $(22,405)$, Trujillo $(19,149)$, Bagua $(16,877)$, Chiclayo $(16,026)$, Tacna $(16,095)$, etc. Puede verse la creciente importancia de algunas provincias de la selva. En cambio109 provincias (76\%) tenían balances negativos, porque expulsaban más población que la que atraían, sobre todo en la sierra, siendo más significativos en: Cajamarca $(-46,275)$, Chota $(-37,971)$, Huamanga $(-37,904)$, Piura $(-36,179)$, Otuzco $(-32,190)$, Puno $(-31,847)$, Huaraz $(-31,196)$, Huancavelica $(-27,545)$, Azángaro (-24,441), etc. (18)

Según el censo nacional de 1972 la migración interprovincial ascendió a 3'500,000 personas. De las 149 provincias del país, sólo 35 (25\%) tenían saldos migratorios positivos, sobresaliendo Lima-Callao (1'260,700), muy alejados seguían Trujillo $(75,105)$, Santa $(68,131)$, Arequipa $(50,192)$, Bagua $(47,366)$, Chiclayo (35,310), Coronel Portillo $(32,409)$, Jaén $(32,115)$, Chancay $(26,900)$, Leoncio Prado (26,573), etc. En total, 112 provincias $(75 \%)$ mayoritariamente exhibían saldos migratorios negativos, apreciándose más en Chota $(-62,815)$, Otuzco $(-50,120)$, Cajamarca $(-48,747)$, Andahuaylas $(-46,072)$, Lucanas $(-39,739)$, Azángaro (-36,024), Huancané $(-33,455)$, Ayabaca $(-32,815)$, Santiago de Chuco $(-30,323)$, Parinacochas $(-29,264)$, Cutervo $(-27,314)$, etc. (19).

Hasta 1981 la migración entre provincias movilizó a 4'500,000 personas. Comparado con principios de 1970, los que se desplazaron al menos una vez de una provincia a otra aumentaron de $25,7 \%$ a $26,6 \%$. Hasta ese año en Lima-Callao vivían cerca de 1'900,000 provincianos (41\% de su población), menor que en 1972. Los migrantes de las décadas de 1950 a 1980 fueron campesinos pobres que se articularon al mercado de bienes y servicios informal y al mercado de trabajo formal. Entre 1981 y 1993 hubo 1'800,000 nuevos migrantes.

\subsubsection{La inmigración a las ciudades}

Entre 1940 y 1960 aumentó la presencia de migrantes en varias de las ciudades principales del país, como Arequipa (de 12 a 27\%), Trujillo (de 27\% a 44\%), Cusco (19\% a $37 \%$ ), Chiclayo (25\% a $36 \%$ ), Puno (de $21 \%$ a $55 \%$ ), Piura (de $16 \%$ a $32 \%$ ) e Iquitos (de $20 \%$ a $33 \%$ ). Hasta 1970 los inmigrantes a Arequipa aumentaron al $38 \%$, Trujillo al $45 \%$, Chiclayo $37 \%$, Cusco $44 \%$, Piura $34 \%$ e Iquitos 35\%. Hasta 1961 los inmigrantes en Lima Metropolitana participaban con el $45 \%$ de la población, aumentando ligeramente hasta 1972 al 46\%. 
En la década de 1980, las migraciones internas se aceleraron especialmente en la sierra central y sur, crecimiento atribuido en gran parte a la fuerza de la violencia política provocando el desplazamiento forzado por el miedo y terror de 500,000 personas, mayormente campesinos. La violencia política desestabilizó el país provocando la muerte de 70,000 personas, principalmente campesinos pobres. Como resultado la emigración del campo aumentó, así como la inmigración en algunas ciudades cercanas a las zonas de conflicto como Huancayo $(47,9 \%)$, Ayacucho $(43,5 \%)$, Abancay $(43,4)$ y Huánuco $(46,3 \%)$.

En la misma década y primeros años de la década de 1990, las migraciones se aceleraron en la selva alta con el aumento de la producción de la coca, ligada en gran parte al narcotráfico. Esto sucedió en San Martín, Ucayali y en la selva de Huánuco. Es grande la proporción de inmigrantes en ciudades intermedias y menores como Tarapoto (46,4\%), Tingo María (48,8\%), Bagua (51,6\%), Chachapoyas (46,3\%), Moyobamba (43,0\%). Fue considerable en una ciudad pequeña como Tocache (52,9\%) e impresionante en Aguaytía (75,8\%).

En Tacna $(51,3 \%)$ y Juliaca $(52,7 \%)$, mayoritariamente los inmigrantes se vinculaban al contrabando. Muchos foráneos de algunas ciudades menores como Huaral (50,2\%), Mala (51,1\%) y Barranca (49,2\%), eran informales. Moquegua $(53,4 \%)$ y Puerto Maldonado $(41,2 \%)$, ciudades vigorizadas por la minería, tenían también muchos inmigrantes, como Chachapoyas $(46,3 \%)$. Las migraciones reforzaron el proceso de urbanización secundaria de las ciudades menores y algunas intermedias. En los primeros años de la década de 1990 los provincianos en Lima Metropolitana declinaron (40,0\%).

\section{Las migraciones dentro del modelo neoliberal}

Este modelo surge ante el agotamiento y colapso del modelo de industrialización y de la estrategia basada en la expansión del mercado interno. Los autores oficiales pertenecen al Banco Mundial y al consenso de Washington, quienes afirman que el único camino para todos los países latinoamericanos era aprovechar sus recursos naturales y exportar artículos manufacturados para buscar una inserción ventajosa en el mercado mundial. Se destaca la necesidad de que el Estado se enfoque a crear un entorno institucional favorable para el libre mercado, que mantuviera la disciplina fiscal, que impulsara la apertura de la economía, que promoviera las inversiones extranjeras, que privatizara sus activos, que desregulara los mercados y que respetara irrestrictamente los derechos de propiedad (20). Se atribuye al crecimiento económico un papel crucial para la reducción de la pobreza, concibiéndolo como generador de oportunidades de incorporación individual al mercado (21).
Las inversiones más importantes en las dos últimas décadas fueron en los sectores primarios (energía, minería, gas, petróleo) y servicios (comunicaciones, electricidad, bancos, líneas aéreas, etc.). Se privatizaron y concesionaron muchos recursos naturales, vías, energía eléctrica, puertos, aeropuertos, etc. En el 2002 las mayores inversiones fueron en comunicaciones (33\%), industrias (17\%), finanzas (15\%), minería (12\%) y energía (5\%). En el 2012 la minería ocupa el primer lugar $(25 \%)$, finanzas (18\%), comunicaciones (17\%), industria (14\%) y energía (14\%). Entre el 2001- 2005 en la minería se invirtieron 4,000 millones de dólares, entre 2006-2010 superó los 11,000 millones.

Las exportaciones mineras representaron en el año 2009 el $54,0 \%$ del total de exportaciones del país, subiendo en el 2010 al 61\%. Según el MEF las principales inversiones extranjeras en el 2002, venían de España (32\%), Reino Unido (17\%), Estados Unidos (13\%) y los Países Bajos (8\%). En el 2012 el 20\% aportaba España, 20\% el Reino Unido, 14\% Estados Unidos y 7\% los Países Bajos. El aporte yanqui dejó de ser dominante. La inversión extranjera directa acumulada entre el 2003 y el 2012 fue de 56,751 millones de dólares.

En la primera década del siglo XXI el PBI tuvo un crecimiento impresionante $(5,8 \%)$, estimulado por el aumento de las exportaciones, sobre todo mineras. Pero, este auge no ha ayudado a una disminución significativa de la pobreza multidimensional $(40 \%)$ en contraste con la pobreza monetaria oficial (28\%). En el 2010 llegó al $31 \%$ (en el campo fue $54 \%$ ), siendo más dramático en la sierra rural (61\%), donde el $28,5 \%$ estaba en situación de extrema pobreza (22).

La explotación de los recursos naturales (especialmente mineros) es rechazada por un sector de la población rural temerosa por de los daños ambientales. Muchas empresas buscan acuerdos con las poblaciones cercanas a las áreas de explotación garantizándoles bienestar y respeto al medio ambiente. El problema se agrava con las empresas ilegales que dañan el ambiente, como en Madre de Dios, donde muchos trabajadores, migrantes la mayoría, se desplazan para extraer oro y depredar bosques, usando la flamante carretera interoceánica.

\subsection{La estructura productiva agropecuaria}

Según los dos últimos censos agropecuarios (1994-2012), las unidades agropecuarias aumentaron de 1'751,091 a 2'213,506, es decir 460,000 nuevas posesiones, mucho mayor al periodo 1972-1994 (361,203). Parte de las nuevas unidades agropecuarias resultan de la sobreparcelación de tierras. En Cajamarca ( 2012) son más las unidades agropecuarias $(329,650)$, pero $89 \%$ son menores de 5 hectáreas, también tiene (2007) el mayor saldo migratorio negativo $(-532,984)$. Hay una relación entre pequeña agricultura y emigración. 
En el periodo 1994-2012 la superficie agropecuaria nacional evolucionó favorablemente de 35'381,108 a 38'742,465 hectáreas, ampliándose la frontera agropecuaria en más de 3’361,000 hectáreas (23). Las unidades y superficie agropecuaria se concentran en la región de la sierra $(68,9 \%$ y $79,7 \%$, respectivamente). Las propiedades mayores de 50 hectáreas disminuyen del 2,7\% (1994) al 1,8\% (2012) del total de unidades agropecuarias, respectivamente. Pero, aumenta la concentración de tierras del $77 \%$ al $80,0 \%$ de la superficie agropecuaria. En el 2012 sólo las tierras de 3,000 hectáreas absorben a más del $55 \%$ de la superficie agropecuaria. También los pequeños predios (menores de 5 has.) aumentan de $73 \%$ al $82,0 \%$. Pero, apenas absorben el 5,8\% y 5,6\%, respectivamente, de la superficie agropecuaria.

Entre los años 1972-1994 y 1994-2012, disminuye el ritmo de crecimiento de la superficie agropecuaria. En el primer periodo las tierras aumentaron 11'835,759 hectáreas, mientras que en el segundo periodo fue de 3'361,000. Es importante el crecimiento sostenido de las unidades agropecuarias en la selva, las cuales entre 1972 y el 2012 se ampliaron de 13,9\% a 20,6\% del total de propiedades. En esta región es importante el aumento de la superficie agropecuaria (de $12 \%$ a más $31 \%$. Entre 1972 y 1994, las tierras crecieron más en la selva (de 2'949,695 a 10'083,349 hectáreas). Hasta 2012 se elevó a 12'032,040 hectáreas.

Entre 1993- 2007 la tasa de crecimiento demográfica rural del departamento de San Martín declinó significativamente a $1,2 \%$. En Ucayali la población del campo alcanzó una tasa negativa $(-0,2 \%)$. Tocache y Aguaytía, pequeñas ciudades, exhibían tasas negativas en contraste con las altas tasas anteriores. El descenso migratorio campesino se asocia con la erradicación de los cultivos de coca.

Entre 1994 y el 2012 el crecimiento de las tierras en la costa muestra un mayor dinamismo aumentando de 2'604,000 a 4'441,000 hectáreas, es decir 1'837,000 de nuevas tierras, tocándole a la agricultura el 38\%. En esta región la ampliación de la frontera agrícola se relaciona con el boom del agro de exportación (hortalizas, frutas, etc.) que requiere de más trabajadores, en parte migrantes.

\subsection{Urbanización y migraciones internas \\ 4.1.1 Urbanización}

Entre 1990 y el 2010 el proceso de urbanización demográfico siguió decreciendo aunque conservándose alto. En el periodo 1993-2007 el ritmo de crecimiento urbano declinó a 2,1\% pero aglutinó a 5'350,000 personas más, aumentando su participación porcentual (76,0\%). Simultáneamente, por esos mismos años, la participación de las áreas rurales se debilitó aun más $(24 \%)$, con casi una nula tasa de crecimiento $(0,01 \%)$. Entre el 20072011 la tasa de urbanización siguió cayendo $(1,9 \%)$ pero con más presencia en el país $(77,3 \%)$, mientras que la tasa rural se torna negativa $(-0,12)$, declinando su población en términos absolutos.

La caída de la dinámica demográfica urbana no ha sido un obstáculo para que el proceso de urbanización avance. Si en 1981 en 37 ciudades se reunía el 46\% de la población del país, en 1993 superaba el 50\%, en el 2007 eran más del 54\%, estimándose en el 2011 en 56\%. Hay una ocupación desigual de nuestro territorio, donde en un espacio pequeño se agrupa la mayor parte de la población. La tasa de crecimiento de Lima Metropolitana disminuyó en los periodos 1993-2007 y 2007-2011 de $2,1 \%$ a $1,9 \%$.La dinámica poblacional de la mayoría de las ciudades grandes, intermedias y menores también declinó, manteniéndose bajas en Arequipa (1,2\%), Huancayo $(1,5 \%)$, Chiclayo $(1,4)$ y Chimbote $(1,1)$, entre otras, y altas en Trujillo $(2,0)$, Piura $(2,2)$, Iquitos $(2,0)$, Moyobamba (3,8\%), Juliaca (2,9\%), etc. En esta última ciudad el contrabando mueve la economía. En Chimbote la extracción y procesamiento de la anchoveta no vuelto a las cifras históricas de las décadas de 1950 y 1960.

Sin embargo, resulta importante la alta y creciente tasa demográfica de algunas ciudades intermedias y menores como Cajamarca (4,1\%), Huaraz (3,0\%), Puerto Maldonado $(4,8 \%)$ y Chachapoyas $(2,8 \%)$ entre 1993 2007 y 2007-2011. El crecimiento demográfico en las tres primeras ciudades se atribuye a la influencia de la minería y su impacto en otras actividades. Chachapoyas crece por la expansión del comercio y servicios, siendo un factor importante el turismo.

La violencia política disminuyó significativamente, contribuyendo a reducir el ritmo de crecimiento demográfico de algunas ciudades intermedias y menores. La represión de la subversión en la sierra rural y la pacificación de vastas zonas, determinó que un grupo de desplazados por la violencia retornara a sus lugares de origen. Pero este regreso no fue muy numeroso, en consecuencia las presiones demográficas, espaciales y sociales se prolongan todavía en Ayacucho, Huancayo, Huánuco, Abancay y Huancavelica, ciudades a las que aún siguen llegando migrantes, aunque relativamente decrecientes.

Por otro lado, con la represión del narcotráfico en la selva disminuyó relativamente la tasa de crecimiento de las ciudades intermedias de Tarapoto y Moyobamba debido al descenso de las migraciones. El impacto demográfico negativo es mayor en Tocache $(-1,1 \%)$ y Aguaytía $(-0,005 \%)$ que disminuyen su población, mostrando tasas negativas. La mayor parte de las ciudades de la selva siguen siendo importantes blancos migratorios a pesar que han declinado. 


\subsubsection{Migraciones internas}

Las migraciones, 1940-1993, entre provincias, tuvieron una evolución histórica favorable, aumentando de 12,8\% a $28,6 \%$ con respecto a la población total. Con el nuevo siglo, se marca un hito ya que en el 2007 se constata que su aporte desciende al 24,9\%. El incremento absoluto entre 1993-2007 llegó a 525,000 personas, cifra bastante menor respecto al periodo 1961-1972 (1'260,000). La caída de la fecundidad y el aumento de la emigración de peruanos al extranjero, en gran parte han contribuido al descenso de los movimientos de población.

Entre 1995 y el 2011, según Richard Web (24), la red vial se elevó de 81,000 a 129,000 kilómetros, de las cuales 17,000 están asfaltados. También la difusión de los servicios de comunicaciones como internet, telefonía móvil, cable mágico contribuyen a que el mundo rural se conecte más dentro y fuera del país. Se aceleran más los flujos de bienes y servicios En el campo el uso extendido de celulares ha reemplazado a los antiguos y obsoletos radios transistores.

\subsubsection{Los saldos migratorios entre provincias}

Hasta 1993 los flujos migratorios entre las 188 provincias existentes involucraron a más de 6’300,00 personas, es decir al 28,6\% de la población del país. Así también 140 provincias $(74,6 \%)$ presentaban saldos migratorios negativos, siendo focos de expulsión de población, acentuándose más en Chota $(-91,812)$, Cutervo $(-65,741)$, Puno (-62,981), Ayabaca $(-61,865)$, Otuzco $(-60,183)$, Jauja (-60,059), Huancavelica $(-59,551)$, Azángaro $(-57,848)$, Andahuaylas (-54,737), Pasco $(-53,117)$, Cajamarca $(-51,450)$, Morropón $(-50,449)$, etc.

Sólo 48 provincias $(23,6 \%)$ tuvieron saldos migratorios positivos, de las cuales los más importantes blancos migratorios fueron las provincias de Lima-Callao (2'0007,836), seguido a considerable distancia de Trujillo $(156,019)$, Arequipa $(130,093)$, Tacna $(76,376)$, Chiclayo $(57,828)$, Santa $(55,514)$, Coronel Portillo $(51,441)$, San Román $(43,771)$, Tocache $(32,487)$, Rioja $(30,398)$, etc. (25).

Hasta el 2007 la migración ascendió a 6'800,000 personas. Hubo 194 provincias, teniendo 142 (73,2\%) saldos migratorios negativos como Chota $(-103,627)$, Puno $(-83,677)$, Cutervo $(-78,473)$, Ayabaca $(-75,557)$, Huancavelica (-75,535), Morropón (-67,331), Huarochirí $(-66,486)$, Jauja $(-64,744)$, Azángaro (-63,778), Pasco $(-62,283)$, Huancabamba $(-59,962)$, Huaraz $(-58,206)$, Tarma (-56,560), Abancay $(-56,767)$, Cajamarca $(-56,259)$, etc. Sólo 52 provincias $(26,8 \%)$ tienen saldos migratorios positivos, como Lima-Callao (2'517,560), Trujillo (210,000), Arequipa (163,366), Tacna $(89,746)$, Chiclayo $(53,833)$, Cusco $(49,027)$, San Román $(45,268)$, Santa $(34,155)$, etc. (26). Hasta el 2011 el volumen migratorio se estima en 6'977,274. Las provincias con saldos migratorios negativos, reafirman su carácter andino y rural, con mayor pobreza y extrema pobreza. La esperanza de vida es menor, la mortalidad infantil alta, el analfabetismo mayor, los ingresos per cápita bajos, etc. Las provincias con saldos migratorios positivos son dominantemente costeñas, con bajos niveles de pobreza, baja desnutrición infantil, mayores ingresos, escaso analfabetismo, etc.

\subsubsection{La inmigración a las ciudades}

En las últimas décadas se fueron consolidando otros espacios del país, como blancos migratorios importantes. Entre 1970-1990 crece la migración a la selva alta. Pero entre 1990-2010 declina relativamente. Aumentan los migrantes a lugares cercanos a centros mineros (Cajamarca, Huaraz y Puerto Maldonado). En Chachapoyas también ocurre pero favorecido por el comercio y servicios.

Entre 1993 y el 2007 se construyeron más carreteras, mejorándose ampliamente otras, posibilitando una mayor conexión vial de poblados rurales con ciudades menores e intermedias, con impactos favorables para la movilidad geográfica. Aunados a otras formas de conexión (telefonía fija, celular, internet, televisión) definitivamente se ha roto el aislamiento de muchos lugares del campo.

Hasta 1993, en 8 ciudades del país el principal componente del crecimiento demográfico fue la inmigración, como en Tacna $(51,3)$, Juliaca $(52,7 \%)$, Huaral (50,2\%), Jaén (51,7\%), Ilo (54,1\%), Moquegua $(53,4 \%)$, Mala $(51,1 \%)$ y Bagua $(51,6 \%)$. A excepción de las tres primeras, consideradas ciudades intermedias, las otras son conglomerados menores de 50,000 habitantes. En otras ciudades la migración fue relevante como en Chachapoyas (46,3\%), Abancay (43,4\%), Ayacucho (43,5\%), Huánuco (46,3\%), Huancayo (47,9\%), Trujillo (44,7\%), Barranca (49,2\%), Puno (44,0\%), Moyobamba (43,0\%), Tarapoto (46,4\%), Tingo María (48,8\%), Puerto Maldonado (41,2\%), Jaén (41,1\%). En este grupo casi todas las ciudades son intermedias, con muchos inmigrantes de sus regiones.

En la primera década del presente siglo la dinámica de las migraciones en las ciudades grandes, intermedias y pequeñas disminuyó. Sólo en Chachapoyas (48,9\%) y Cajamarca $(37,8 \%)$ aumentaron significativamente los foráneos. En Puerto Maldonado hay una ligera declinación porcentual, pero en términos absolutos la migración se duplica. En otras ciudades las migraciones se reducen en cifras absolutas como en Chimbote, Huacho, Cerro de Pasco, Tumbes, Pucallpa, Tingo María, Huaral, Mala, Tarma. Esto ocurre con más énfasis en Tocache $(-1,6 \%)$, pero más en Aguaytía $(-3,7 \%)$ donde la inmigración disminuye bastante. El ritmo de 
crecimiento de las migraciones (1993-2007) en algunas ciudades superó al de la población total como ocurrió en Chachapoyas $(3,1 \%)$, Cajamarca $(4,4 \%)$ y Huancavelica $(2,1 \%)$. En otras ciudades se conservan altas a pesar de caer, como en Puerto Maldonado (4,6\%), Moyobamba $(3,7 \%)$, Andahuaylas (2,9\%), Huaraz (2,5\%), Tarapoto $(2,7)$, Bagua $(2,4 \%)$.

En ciudades grandes como Trujillo, Arequipa y Chiclayo, a diferencia de décadas anteriores, las tasas de crecimiento de las migraciones fueron bajas como también sucedió en aglomeraciones intermedias como Piura, Huancayo, Iquitos y Tacna. Hasta el año 2011 la caída de las migraciones prosigue en la mayoría de ciudades como en Arequipa (37,1\%) y Trujillo (41\%). Pero, en Cajamarca, Huaraz y Puerto Maldonado, la participación migratoria se eleva a 39\%,33\%, 41,0\%, respectivamente, atraída por los impactos favorables de la minería. En Chachapoyas esta se acerca al $50 \%$ por la mayor importancia de las actividades de servicios. El lugar de origen de los migrantes, en la mayoría de los casos es del mismo departamento o región donde se encuentra la ciudad. En 11 ciudades hay más migrantes de otros departamentos, como en Tacna, (52\% son puneños), Puerto Maldonado (46,5\% son cusqueños) y en Tumbes el $45 \%$ son piuranos.

\subsubsection{Las migraciones en Lima Metropolitana}

Desde 1950 se ve con más énfasis la orientación de los principales movimientos migratorios a Lima, como expresión del centralismo económico, político y demográfico del país. "Es una consecuencia del proceso colonial y posteriormente del proceso republicano de conformación del Estado sobre esas bases, inclusive en sus dimensiones culturales. Hasta que la explosión demográfica y el incipiente capitalismo industrial en el siglo XX convierten el centralismo administrativo y económico, también en una conglomeración humana, en un centralismo demográfico, junto con la frustración de un proyecto industrial autónomo" (27). La centralización económica es por la ubicación del gobierno, cuyas finanzas han girado históricamente en torno de la economía exportadora, lo que implica que el sistema tributario y burocrático está diseñado para centralizar los flujos de impuestos y decidir su asignación desde Lima (28)

La capital empezando el siglo XXI tenía más del 40\% de la población urbana, el $54 \%$ del PBI nacional, $70 \%$ del PBI industrial, $52 \%$ de los servicios de gobierno y $90 \%$ de la recaudación fiscal. La banca colocaba el 75\% de los préstamos, concentraba el $85 \%$ de las industrias y el $90 \%$ de los servicios comerciales, crediticios y financieros. La pobreza cayó entre el 2004-2007 de 32\% a 19\%.

Entre 1940-1972 las migraciones a Lima se intensificaron, en 1972 representó el 46,0\% de la población capitalina.
Después declinó en el 2007 al 32,5\% y en el 2011 al 31,0\%. Entre 1961-1972 la tasa migratoria de Lima fue de 5,4\%, cayendo entre $1993-2007$ al 0,7\% y entre 2007 2011 al 0,5\%. Entre 1981-1993 hubo 609,000 nuevos migrantes, entre 1993- 2007 fue sólo de 263,000. La declinación de la inmigración a la capital es notoria entre 1990-2011, se explica por la reducción de la fecundidad y por la mayor emigración de peruanos al extranjero. También por las movilizaciones a otras regiones dentro del país. Los inmigrantes provienen de todos los lugares del país, pero en especial cercanos a la capital.

\subsubsection{De las migraciones internas a las migraciones internacionales}

Dentro de este modelo económico la migración interna declina con un bajo ritmo de crecimiento. En cambio la migración internacional se muestra más vigorosa. Si bien los desplazamientos internos son más numerosos, resultan menos intensos y relativamente decrecientes. Por el contrario, la emigración al extranjero siendo menor es más intensa. Entre 1993 y el 2007 la tasa de crecimiento de la migración externa fue de 4,9\%, mientras que la interna apenas llegó al 0,5\%. En el tramo 2007-2011 la tasa externa llega a 7,9\%, mientras que la interna fue apenas del 0,5\%. Entre 1990 y el 2011 cerca de 2,5 millones de compatriotas se fueron del país (29), siendo $66 \%$ provincianos. Entre el 2001 y el 2011 se intensifica la emigración ya que salieron 1'710,000 peruanos. Sólo en el año 2009 se fueron 238,000, reduciéndose en el 2011 a 203,000.En esta primera década hay un crecimiento impresionante de la economía, pero con diversos mecanismos de exclusión que originan inequidad y descontento. Estos problemas evidencian la distancia entre el empleo y el bienestar, pues en medio de una recuperación y crecimiento importante han emigrado hacia el exterior cientos de miles de peruanos en busca de mejores oportunidades. La emigración de peruanos en estas últimas dos décadas son social y culturalmente populares. Los lugares de destino se encuentran limitados por las condiciones económicas. Así, cuesta más irse a lugares más alejados (Japón, Australia, Europa), predominando migrantes de sectores medios. Pero, los beneficios son mayores. En cambio cuesta menos cuando muchos peruanos se movilizan a países más cercanos (Chile, Argentina, Bolivia) donde los beneficios son menores.

\section{Conclusiones}

La dinámica de las migraciones internas en la sociedad peruana, históricamente está relacionada con los cambios operados en su estructura productiva, particularmente, en sus sectores claves, relacionados con los modelos de desarrollo primario-exportador, de industrialización y neoliberal.

La primacía del modelo primario-exportador en las primeras décadas del siglo XX estimuló la migración 
campesina hacia los centros de producción y explotación agrícolas, mineras y, en menor medida, caucheras más importantes del país, a través del sistema del enganche y del yanaconazgo.

Las migraciones internas, en la primera mitad del siglo XX, asumieron un mayor rol, tuvieron que ver con el aumento de la población de los principales valles y haciendas de la costa norte, de los poblados y ciudades mineras de la sierra central. expandieron demográficamente Lima.

En las primeras décadas del siglo XX las migraciones a Lima se dan dentro un proceso de modernización y diversificación de la economía urbana. Los primeros grupos de migrantes pertenecían a las clases medias y altas provincianas que venían a estudiar, trabajar o residir definitivamente en la capital. En 1931 representaban el $36 \%$ de la población de Lima.

Desde de la segunda mitad del siglo XX, con la industrialización se intensifica la migración acelerando el proceso de urbanización. La pesca, minería y agricultura favorecen las migraciones. Pero el agro andino se mantuvo inalterable acentuando la expulsión de población.

Por estas décadas la composición social de los migrantes cambia, destacando por su origen popular y campesino, articulándose de diferentes formas a la economía urbana. Los saldos migratorios en 1961 y 1972 en la mayoría de las provincias fueron negativos, principalmente en la sierra. Son pocas las provincias con saldos positivos, destacando por su volumen Lima

El proceso de urbanización se acelera en las décadas de 1950 y 1960, cayendo en los años siguientes. En la década de 1980, en diversos lugares de la selva y de la sierra, se aceleraron las migraciones y la urbanización secundaria por el incremento del narcotráfico y la violencia subversiva.

El aporte de las migraciones internas aumentó entre 1940 y 1993 del 13\% a cerca del 29\% de la población del país. En la década de 1970 crecieron en la mayoría de las ciudades, sobre todo, menores. En Lima cayó del $46 \%$ al $41 \%$ abriéndose otros espacios de atracción de población.

A partir de la década de 1990, debido al colapso del modelo de industrialización, empieza a asentarse el modelo neoliberal, acentuando su patrón primario-exportador. El proceso de urbanización avanza pero pierde intensidad como en muchas ciudades hasta la primera década del 2000.En los últimos años es más notorio el descenso absoluto de la población rural.

El aporte de las migraciones internas, entre 1993 y el 2011, se reduce del $29 \%$ al $24 \%$ con respecto a la población nacional. Los saldos migratorios negativos en el 2007 son más del 75\% de las provincias, con menor desarrollo. También se acentúa la caída de la migración en la mayoría de ciudades. En algunas crece ligada principalmente a la minería y servicios.

Con la declinación de la migración interna, se acrecienta significativamente la migración internacional. En el periodo 1993-2011, la migración interna apenas alcanzó, en promedio, una tasa de crecimiento de $0,5 \%$ anual y la migración al extranjero tuvo una tasa muy superior $(5,0 \%)$.

\section{NOTAS}

(1) Singer, Paul, pags. 40-43

(2) Llona Mariana, Ramírez Daniel y Zolezzi Mario, pag

(3) Eguren, Fernando y Pérez Edelmira, pags. 58-60.

(4) Webb, Richard. Pag.

(5) Barba, Carlos, pag. 85

(6) Pennano, Guido, pag. 14.

(7) Roel, Virgilio, pag. 79

(8)Contreras, Carlos, pag. 12

(9)Forma de contrato basado en un adelanto en dinero o especies que se daba al trabajador que después lo pagaba con trabajo.

(10) Era una mezcla de renta en trabajo y productos. A veces era dinero que se daba por usar una parcela dentro de las tierras de la hacienda.

(11) Eguren, Fernando y Fernández-Baca, Fabián, pag. 46

(12) Romero, Emilio y Lévano César, pag. 24

(13) Barba, Carlos, pag. 87

(14) Ferrero, Romulo, pags. 22-23

(15) Web, Richard, pag. 193

(16) ONEC-INEI

(17) Es la diferencia del número de inmigrantes menos el de emigrantes

(18) ONEC, tabulados

(19) ONEC Tabulados

(20) Barba, Carlos, pag. 91

(21) Barba, Carlos, pag. 97

(22) BID- CIES, pag. 6

(23) INEI, pag. 4

(24) Web, Richard, pag. 193

(25) INEI, tabulados

(26) INEI, tabulados

(27) PNUD, pag. 23.

(28) Gonzales de Olarte, Efraín, pag. 28.

(29) INEI,pag. 16

\section{Literatura citada}

Anuario Estadístico del Perú, Lima, 1940

Barba, Carlos. 2004. "Los enfoques latinoamericanos sobre la política social. Más allá del consenso de Washington". Espiral, setiembre-diciembre, Año /vol. XI, N 031, Universidad de Guadalajara, México, 2004.

BID- CIES. "Perú. 1970. ATLAS de la pobreza, departamental provincial, distrital 2007-2009.

CEPD. Informe Demográfico del Perú, 1970

Llona, M., Ramírez D., Zolezzi, M. 2004. "Las ciudades intermedias: Su rol en el desarrollo del país" en "Las ciudades en el Perú”, DESCO, Lima, 2004.

Contreras, Carlos.1994. "Sobre los orígenes de la explosión demográfica en el Perú. 1876- 1940”, IEP, Lima, 1994. 
Eguren Fernando y Fernández-Baca Fabián. 2005.

"Producción algodonera e industria textil en el Perú", DESCO, Lima, 1981.

Eguren, Fernando, Pérez, Edelmira y otros. 2005. "nueva ruralidad y competitividad territorial", Centro Ideas, Cajamarca, 2005.

INEI. Estadística de la emigración internacional de peruanos e inmigración de extranjeros, 1990-2011.

INEI. Censos de Población y Vivienda 1940, 1961, 1972, 1981, 1993 y 2007

INEI. Censo Nacional agropecuario, 1994

INEI-Ministerio de Agricultura. Resultados definitivos, IV Censo Nacional Agropecuario 2012, Lima, 2013.

INEI. "Perú: Migraciones internas 1993-2007”, Lima, diciembre 2008

Ferrero, Rómulo. "El desarrollo económico en el Perú en el período 1950-64", Cámara de Comercio de Lima, 1965.

González de Olarte, Efraín.1992. "La economía regional de Lima. Crecimiento, urbanización y clases populares", IEP, Lima 1992.

Ministerio de Energía y Minas. 2013. Boletín Estadístico minero energética, Lima, 2013.

ONEC. Censos Nacionales agropecuarios, 1961 y 1972

Pennano, Guido. 1979. "La regionalización en el Perú: Antecedentes y planteamientos". CIUP, Lima, 1979

PNUD. 1971. "Informe sobre Desarrollo Humano. Perú 2006. Hacia una descentralización con ciudadanía"

Roel, Virgilio. 1971. "Esquema de evolución económica", Edit. Amauta, Lima, 1971

Romero, Emilio y Lévano, César. "Regionalización y centralización", en Guido Pennano, "La Regionalización en el Perú: Antecedentes y planteamientos".Singer. "Economía política de la urbanización”, Edit. Siglo XXI, México, 1975.

Web, Richard. 2013. "Conexión y despegue rural", USMP, fondo editorial, Lima, 2013. 